Available online on 17.04.2021 at http://jddtonline.info
Open Access to Pharmaceutical and Medical Research
unrestricted non-commercial use(CC By-NC), provided the original work is properly cited

Open Access Full Text Article

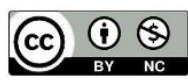

Research Paper

\title{
Comparative study of the anticoagulant powers of the aqueous macerate, ethanolic macerate and aqueous decoction of the leaves of Uvaria chamae P. Beauv. (Annonaceae)
}

\author{
Bamba Bourahima ${ }^{1 *}$, Benie Comoé Koffi Donatien ${ }^{1}$, Doukourou Dahiro Noél ${ }^{1}$, Wacoubo Brice Herman², \\ Tape Doris Leslie ${ }^{2}$, Dasse Sery Romuald ${ }^{2}$, Ouattara Karamoko ${ }^{1}$ \\ ${ }^{1}$ Laboratory of Biochemical Pharmacodynamics -UFR Biosciences, Félix Houphouet-Boigny University of Cocody Abidjan 22 BP 582 Abidjan 22
}

${ }^{2}$ Immunology and Hematology Department, UFR Medical Sciences in Abidjan, Felix Houphouet Boigny University, Abidjan, Côte d'Ivoire

Article Info:

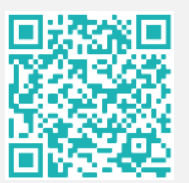

\section{Article History:}

Received 17 Feb 2021

Review Completed 26 March 2021

Accepted 06 April 2021

Available online 17 April 2021

Cite this article as:

Bamba B, Benie CKD, Doukourou DN, Wacoubo BH, Tape DL, Dasse SR, Ouattara K, Comparative study of the anticoagulant powers of the aqueous macerate, ethanolic macerate and aqueous decoction of the leaves of Uvaria chamae P. Beauv. (Annonaceae), Journal of Drug Delivery and Therapeutics. 2021; 11(2-s):82-88

DOI: http://dx.doi.org/10.22270/jddt.v11i2-s.4668
Abstract

Data on the anticoagulant power of Uvaria chamae, a plant used in traditional medicine, remain unknown despite its many therapeutic and biological virtues. The present study aimed to compare the anticoagulant effects of aqueous macerate, ethanolic macerate and aqueous decoction of $U$. chamae leaves. The anticoagulant activity of macerated and decocted $U$. chamae was evaluated in vitro against endogenous and exogenous coagulation pathways in a pool of displaced normal plasmas. These two pathways are explored using two global and chronometric tests including Cephalin-Kaolin Time (TCK) and Prothrombin Time (TQ). The results obtained revealed that the incubation time of $U$. chamae macerates and decoctions with plasma significantly influences their anticoagulant power. This evaluation showed that these macerated and decocted products exerted anticoagulant power at concentrations dependent on these two coagulation pathways. This anticoagulant power at the level of the aqueous decocted was more significant $(\mathrm{P}<0.001)$ on these two coagulation pathways but it was more marked on the endogenous pathway than on the exogenous pathway. This anticoagulant power at the level of the aqueous decocted was more significant $(\mathrm{P}<0.001)$ on these two coagulation pathways but it was more marked on the endogenous pathway than on the exogenous pathway. This Ivorian plant could thus be considered as a natural source of anticoagulant agents for medicinal purposes.

Keywords: Uvaria chamae, Anticoagulant, Aqueous macerate, Ethanolic macerate, Aqueous decocted

*Address for Correspondence:

Bamba Bourahima, Laboratory of Biochemical Pharmacodynamics -UFR Biosciences, Félix Houphouet-Boigny University of Cocody, Abidjan 22 BP 582 Abidjan 22

\section{INTRODUCTION}

Cardiovascular disease, which causes many deaths each year, remains a public health problem ${ }^{1}$. Thrombosis is one of the main causes of thromboembolic disorders affecting thousands of people worldwide 2 . It also causes strokes, ischemic heart disease, traumatic injuries and hypertension. The treatment of thrombosis uses thrombolytic agents with anticoagulant and antiplatelet activity.

Thus, anticoagulants play an essential role as mediators in the treatment and prevention of thromboembolic disorders 2. By inhibiting clotting, they prevent the formation of blood clots so as to prevent the onset of diseases where these formed clots will migrate and clog small vessels.

In addition, many anticoagulants used act at different levels of the coagulation cascade and are divided into three classes: two classes of classic anticoagulants (heparin and antivitamin $\mathrm{K}$ ) and the class of newer anticoagulants $3,4,2$. The most commonly used are heparins that act on coagulation with the anti-thrombin cofactor, which is a physiological inhibitor of coagulation. Although heparins are indicated in the prophylaxis and treatment of thromboembolic diseases, they often cause allergies due to their animal origin and nevertheless expose to a risk of thrombocytopenia ${ }^{5,3}$.

In this context, the use of medicinal plants becomes an important alternative route for the search for new natural anticoagulant molecules with fewer side effects.

Among these medicinal plants, Uvaria chamae P. Beauv. is a medicinal plant widely used in Côte d'Ivoire in the treatment of dysentery, wounds, haemorrhages, sore throats and respiratory disorders 6,7. Multiple extracts from different parts of the species have reportedly expressed significant activities in the treatment of dysentery, cancer and diabetes 8,9. Other previous studies have shown the antibacterial, antioxidant 8 , and anti-inflammatory 10 powers of Uvaria chamae. 
However, in spite of some studies carried out on this plant, the data on the anticoagulant activity of Uvaria chamae remain unknown.

The present study aims to compare the anticoagulant effects of aqueous macerate, ethanolic macerate and aqueous decoction of $U$. chamae leaves.

\section{MATERIAL AND METHODS}

\section{Plant material}

The leaves of Uvaria chamae were washed in distilled water, cut into small pieces and then dried at room temperature $\left(25\right.$ to $30^{\circ} \mathrm{C}$ ) to better preserve the molecules sensitive to heat and light for three weeks. These dried leaves were ground into a fine powder using a traditional mortar. The powder obtained was stored in an airtight bottle. This powder was used to prepare the various macerated and decocted leaves.

\section{Preparation of aqueous macerate and ethanolic macerate $96 \%$}

Aqueous and ethanolic macerate $96 \%$ of Uvaria chamae leaves were prepared according to the method of 11 with slight modifications as reported by 12 in their previous work. One hundred grams (100 g) of powder of this plant was macerated in 1 liter of distilled water under agitation with a blinder (Nasco $\AA$, China) for the aqueous macerate. As for the $96 \%$ ethanolic macerate, a mass of twenty grams (20 g) of powder was macerated in $160 \mathrm{ml}$ of ethanol (96\%).

Then, the mixture of each macerate was wrung out in a clean cloth square, filtered successively twice on absorbent cotton and once on filter paper (Whatman ${ }^{\circledR} 3 \mathrm{~mm}$ paper). This filtrate was then slowly dried in an oven at $50^{\circ} \mathrm{C}$ for 72 hours for each macerate.

Finally, the powder obtained (total aqueous macerate or $96 \%$ ethanolic macerate) was stored in an airtight jar and kept in the refrigerator at $+4{ }^{\circ} \mathrm{C} 13$.

\section{Preparation of aqueous decocted}

A mass of $100 \mathrm{~g}$ of fine vegetable powder has been added to $1 \mathrm{~L}$ of distilled water and the mixture is boiled for 15 minutes as described by 12 in their previous work. After cooling, the decoction (the mixture) was wrung out in a clean cloth square, then filtered successively twice on absorbent cotton and once on filter paper (Whatman ${ }^{\circledR} 3 \mathrm{~mm}$ paper). The resulting filtrate was then slowly dried in an oven at $50^{\circ} \mathrm{C}$ for 72 hours. The powder obtained or aqueous decoction was stored in a sterile and dry bottle.

\section{Preparation of the (standard) displaced plasma pool}

The depleted plasma pool is a mixture of depleted plasmas from 10 samples of untreated healthy individuals, aged 25 to 30 years, with normal and comparable TQ and TCK. The blood samples to be destroyed came from the immunology and hematology laboratory of the University Hospital of Cocody. These different blood samples from each individual were collected by venipuncture in a plastic tube on a $3.1 \%$ sodium citrate solution in a ratio of 1 volume to 9 volumes of blood. The unmodified and unprocessed blood was then centrifuged for 10 minutes at $3000 \mathrm{rpm}$ to obtain a plateletpoor plasma. The mixture of these displaced plasmas (standard plasma) was stored at low temperature $\left(-10 \mathrm{C}^{\circ}\right)$ until use ${ }^{14}$.

\section{Measurement of the anticoagulant activity of the endogenous pathway}

The evaluation of the anticoagulant activity of macerated and decocted $U$. chamae against the endogenous coagulation pathway was performed using the Cephalin-Kaolin Time (TCK) test 15

This test consists of measuring the clotting time at $37^{\circ} \mathrm{C}$ of a displaced and citrated plasma in the presence of phospholipid (cephalin) which is usually kaolin and calcium as a trigger 15 .

Thus, this anticoagulant activity of macerated and decocted U. chamae against the endogenous coagulation pathway was evaluated according to the method described by 14 with some modifications. In order to determine the incubation time for optimal anticoagulant activity, $10 \mu \mathrm{L}$ of the different macerated and decocted $(25 \mathrm{mg} / \mathrm{mL})$ were added to $90 \mu \mathrm{L}$ of the platelet-poor plasma. An aliquot of $50 \mu \mathrm{L}$ of this mixture was then incubated at $37 \mathrm{C}^{\circ}$ for variable times $(1 ; 5 ; 10 ; 15$; 20 and 25 minutes). After incubation, $50 \mu \mathrm{L}$ of cephalinkaolin solution was added and the mixture was reincubated at $37 \mathrm{C}^{\circ}$ for 3 minutes. Coagulation was then triggered by the addition of $50 \mu \mathrm{L}$ of an aqueous solution of $0.025 \mathrm{M}$ $\mathrm{CaCl} 2$. The coagulation time was determined using an optical coagulometer (BIO SOLEA 2, France) based on the change in light transmission from the addition of calcium to the formation of the fibrin clot.

After determination of the incubation time for obtaining a high anticoagulant activity, the anticoagulant power of the different concentrations of macerate, decocted and Lovenox® (standard anticoagulant in $0.9 \% \mathrm{NaCl}$ ) was finally evaluated under the same conditions as for the optimal incubation time.

A longer coagulation time in the presence of the different macerates and decocted compared to that of the negative control indicates that these macerates and decocted exert an anticoagulant activity with respect to this coagulation pathway.

\section{Measurement of the anticoagulant activity of the exogenous pathway}

Anticoagulant activity against the exogenous coagulation pathway has been evaluated using a coagulation test called prothrombin time (PT) or prothrombin level (PT), which allows for a global exploration of factors in the exogenous coagulation pathway ${ }^{15}$.

This test consists of measuring the clotting time at $37 \mathrm{C}^{\circ}$ of a platelet-poor plasma in the presence of a mixture of tissue factor, phospholipids (thromboplastin) and calcium. The exogenous pathway factors are thus activated and the time to clot formation is measured 15 .

The effect of the different macerated and decocted products on the exogenous coagulation pathway was evaluated according to the method described by 14 with some modifications.

The effect of the incubation time of the different plasma macerates and decoctions on their anticoagulant power was determined. Thus, a volume of $10 \mu \mathrm{L}$ of the different macerated and decocted products $(25 \mathrm{mg} / \mathrm{mL})$ was added to $90 \mu \mathrm{L}$ of standard plasma. An aliquot of $50 \mu \mathrm{L}$ of this mixture was then incubated at $37 \mathrm{C}^{\circ}$ for different times $(1 ; 5 ; 10 ; 15$; 20 and 25 minutes). After incubation, coagulation was initiated by the addition of $100 \mu \mathrm{L}$ of thromboplastin preincubated at $37 \mathrm{C}^{\circ}$ for 15 minutes, and the time to fibrin clot formation was then automatically measured using the coagulometer. 
After determination of the optimal incubation time for a better inhibition of the exogenous coagulation pathway, the anticoagulant power of different concentrations of the macerated and decocted products was evaluated. It was carried out under the same conditions and at the optimal incubation time. A $0.9 \% \mathrm{NaCl}$ solution was used as a negative control.

A coagulation time that is longer than that of the negative control explains why macerated and decocted exert an anticoagulant effect with respect to this coagulation pathway ${ }^{14}$.

\section{Statistical analysis}

The graphical representation of the data was made using Graph Pad Prism 5.0 software (Microsoft U.S.A). The results of the tests carried out are expressed in average \pm SD. The twoway ANOVA test followed by Bonferroni posttests were used to determine significance rates and multiple comparisons. The difference between two values is considered significant when $\mathrm{P} \leq 0.05$.

\section{RESULTS}

\section{Anticoagulant activities of the endogenous pathway}

The results obtained revealed that the incubation time of the aqueous decoction of $U$. chamae with plasma has a very significant influence $(\mathrm{P}<0.001)$ on the anticoagulant power (Figure 1). Incubation of the negative control $(0.9 \% \mathrm{NaCl})$ during the different times $(1 ; 5 ; 10 ; 15$ and 20 minutes) did not influence the clotting time. However, in the presence of the aqueous and ethanolic macerate, a slight elongation of the insignificant TCK $(\mathrm{P}>0.05)$ was observed (Figure 1).

However, from the first minute, compared to the negative control (34.36 s), the incubation of the aqueous decocted of $U$. chamae with the plasma increased significantly $(\mathrm{P}<$ 0.001 ) with a TCK of $169.57 \mathrm{~s}$ (4.93 times higher). In addition, this incubation recorded TCK of $206.1 \mathrm{~s}$ (6.02 times higher), $217.90 \mathrm{~s}$ (6.15 times higher), $291.83 \mathrm{~s}$ (8.06 times higher), and $289.23 \mathrm{~s}$ (8.33 times higher) at 5; 10; 15, and 20 minutes, respectively, compared with negative controls (Figure 1).

It is clear that the aqueous macerate, ethanolic macerate and aqueous decocted of $U$. chamae have anticoagulant activity positively correlated with incubation time. Thus, incubation for 15 minutes was the preferred time to achieve high anticoagulant activity against the endogenous coagulation pathway (Figure 1).

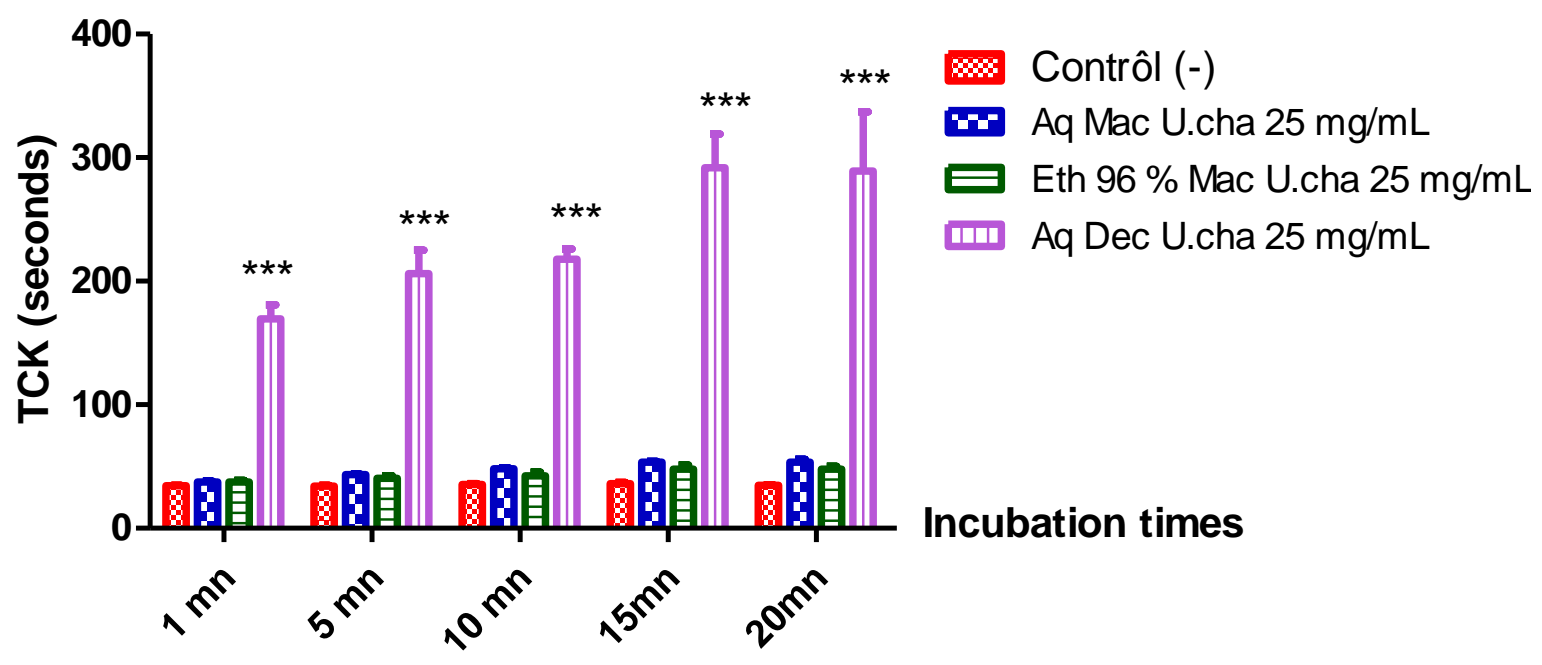

Figure 1: Effect of incubation time of $U$. chamae macerated and decocted $U$. chamae with plasma on the TCK

Each value represents the mean \pm SEM of three trials. Significance at $* \mathrm{P}<0.05,{ }^{* *} \mathrm{P}<0.01,{ }^{* * *} \mathrm{P}<0.001$ versus Control (-); Aq Mac: Aqueous Macerate, Eth 96\% Mac: Ethanolic Macerate 96\%, Aq Dec: Aqueous Decocted, U. cha: Uvaria chamae, TCK: Koalin Cephalin Time

In the second step, the optimum incubation time of $15 \mathrm{~min}$ was chosen for the evaluation of the anticoagulant power of macerated and decocted $U$. chamae against the endogenous coagulation pathway.

The results obtained show that aqueous decoction of $U$. chamae is capable of significantly prolonging $(\mathrm{P}<0.001)$ at TCK-dependent concentrations (Table I).

Furthermore, there is no significant difference $(P \geq 0.05)$ between standard plasma (31.27 s) and negative control (36.20 s) on TCK elongation. Aqueous and ethanolic macerate showed a slight increase in TCK elongation (Table I).

These aqueous and ethanolic macerates of $U$. chamae do not have a significant inhibitory effect on the endogenous coagulation pathway. In contrast to the macerates, the aqueous decocted of $U$. chamae at $25 \mathrm{mg} / \mathrm{mL}$ has a TCK of $8.05(291.83 \mathrm{~s})$ times higher than that of the negative control (36.2 s) and 1.52 times higher than that of Lovenox (191.93 s) at $0.25 \mathrm{mg} / \mathrm{mL}$. However, these prolongations remain well below that of Lovenox (TCK > $600 \mathrm{~s}$ at $0.49 \mathrm{mg} / \mathrm{mL}$ ) (Table I). 
Table I: Effects of macerate and decoction concentrations of Uvaria chamae and Lovenox on TCK

\begin{tabular}{|c|c|c|}
\hline Samples/Plant extracts & $\begin{array}{l}\text { Concentration in plasma } \\
(\mathrm{mg} / \mathrm{mL})\end{array}$ & TCK (seconds) \\
\hline Standard plasma & - & $31,27 \pm 0,64$ \\
\hline \multirow[t]{3}{*}{ Control (-) } & - & $36,20 \pm 0,82$ \\
\hline & 25 & $53,43 \pm 0,67$ \\
\hline & 10 & $47,90 \pm 1,07$ \\
\hline \multirow[t]{5}{*}{ Aqueous Macerate of Uvaria chamae } & 5 & $42,60 \pm 1,02$ \\
\hline & 2,5 & $38,73 \pm 0,52$ \\
\hline & 1 & $37,20 \pm 1,55$ \\
\hline & 25 & $47,80 \pm 3,46$ \\
\hline & 10 & $43,60 \pm 2,54$ \\
\hline \multirow{3}{*}{$\begin{array}{l}\text { Ethanolic Macerate } 96 \% \text { of Uvaria } \\
\text { chamae }\end{array}$} & 5 & $40,57 \pm 0,95$ \\
\hline & 2,5 & $38,47 \pm 0,84$ \\
\hline & 1 & $37,67 \pm 0,86$ \\
\hline \multirow{5}{*}{ Aqueous Decocted of Uvaria chamae } & 25 & $291,83 \pm 27,41 * * *$ \\
\hline & 10 & $233,60 \pm 6,39 * * *$ \\
\hline & 5 & $138,67 \pm 10,54 * * *$ \\
\hline & 2,5 & $62,97 \pm 3,80 *$ \\
\hline & 1 & $41,53 \pm 2,48$ \\
\hline \multirow{3}{*}{$\begin{array}{l}\text { Lovenox (mg/mL, reference } \\
\text { molecule) }\end{array}$} & 0,49 & $>600 * * *$ \\
\hline & 0,33 & $539,07 \pm 14,93 * * *$ \\
\hline & 0,25 & $191,93 \pm 25,04 * * *$ \\
\hline
\end{tabular}

Each value represents the mean \pm SEM of three trials. Significance at $* \mathrm{P}<0.05$; $^{* *} \mathrm{P}<0.01$;

*** $\mathrm{P}<0.001$ versus Control (-). TCK: Koalin Cephalin Time

\section{Anticoagulant activities of the exogenous pathway}

The results obtained indicated that the incubation time of $U$. chamae macerate and decocted with plasma has a significant influence $(\mathrm{P}<0.01)$ on their anticoagulant power (Figure 2). Incubation of the negative control $(0.9 \% \mathrm{NaCl})$ did not influence the prothrombin time (TQ) at any incubation time (1; 5; 10; 15 and 20 minutes), whereas in the presence of macerated and decocted $U$. chamae, the prolongation of the TQ was significant and time-dependent (Figure 2).

The aqueous macerate and aqueous decocted of $U$. chamae recorded significant and high TQ values of $19.10 \mathrm{~s}$ and 32.96 $\mathrm{s}$, respectively, at 20 minutes' incubation compared to the negative control (14.93 s). These TQ were higher than those at $1 ; 5 ; 10$ and 15 minutes' incubation. The ethanolic macerate $U$. chamae indicated a significant and high TQ (19.56 s) at 15 minutes of incubation compared to $1 ; 5 ; 10$ and 20 minutes of incubation (Figure 2).

Macerated and decocted aqueous $U$. chamae have anticoagulant activity positively correlated with incubation time. Furthermore, 15 minutes' incubation of the ethanolic macerate with plasma was the preferred time to achieve high anticoagulant activity against the exogenous coagulation pathway. Aqueous and decocted aqueous macerate of $U$. chamae showed maximum anticoagulant activity (TQ) after 20 minutes of incubation (Figure 2). 


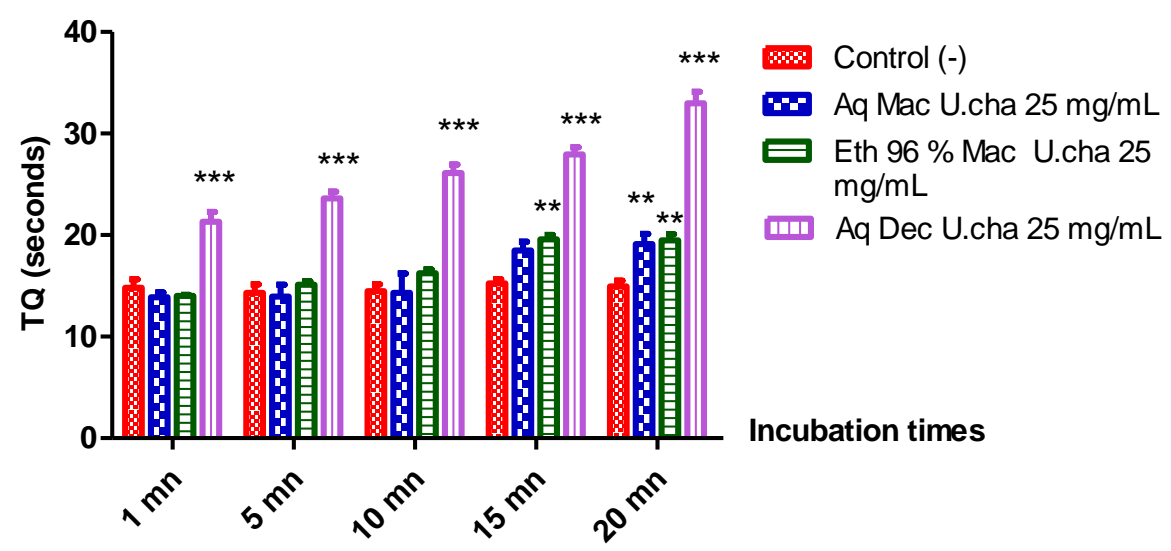

Figure 2: Effect of incubation time of macerated and decocted U. chamae with plasma on the TQ.

Each value represents the mean \pm SEM of three trials. Significance to $* \mathrm{P}<0.05, * * \mathrm{P}<0.01, * * * \mathrm{P}<0.001$ versus Control $(-)$, Aq Mac: Aqueous Macerate, Eth 96\% Mac: Ethanolic Macerate 96\%, Aq Dec: Aqueous Decocted, U. cha: Uvaria chamae, TQ: Quick Time

Two optimal incubation times (15 $\mathrm{min}$ and $20 \mathrm{~min})$ were retained for the evaluation of the anticoagulant power of the macerated and decocted plants with respect to the exogenous route of coagulation.

The results obtained reveal that different macerated and decocted $U$. chamae are capable of significantly lengthening the TQ at TQ-dependent concentrations (Table II).

Furthermore, there is no significant difference $(P \geq 0.05)$ between the standard plasma (13.77 s) and the negative control (15.26 s) on TQ elongation. However, in the presence of the different $U$. chamae macerates and decocted, TQ elongation was significant and increased with concentration (Table II).

Aqueous and ethanolic macerates of $U$. chamae had no significant inhibitory effect $(\mathrm{P}>0.05)$ on the exogenous coagulation pathway at low concentrations $(1 ; 2.5 ; 5$ and 10 $\mathrm{mg} / \mathrm{mL}$ ), whereas at $25 \mathrm{mg} / \mathrm{mL}$ they recorded significant clotting times (TQ) of $18.47 \mathrm{~s}$ and $19.57 \mathrm{~s}$, respectively. On the other hand, a more significant inhibitory effect $(\mathrm{P}<0.001)$ was observed for the aqueous decoction of $U$. chamae in the order of $22.27 \mathrm{~s}, 24.03 \mathrm{~s}$ and $27.93 \mathrm{~s}$ at 5; 10 and $25 \mathrm{mg} / \mathrm{mL}$, respectively (Table II).

Table II: Effects of Uvaria chamae macerate and decoction concentrations with plasma on TQ

\begin{tabular}{lcl}
\hline Samples/Plant extracts & $\begin{array}{l}\text { Concentration in plasma } \\
\text { (mg/mL) }\end{array}$ & TQ (seconds) \\
\hline Standard plasma & - & $13,77 \pm 0,11$ \\
Control (-) & 25 & $15,26 \pm 0,37$ \\
& 10 & $18,47 \pm 0,90 * *$ \\
Aqueous Macerate of Uvaria chamae & 5 & $15,53 \pm 0,42$ \\
& 2,5 & $14,47 \pm 0,19$ \\
Ethanolic Macerate 96 \% of Uvaria & 1 & $14,20 \pm 0,66$ \\
chamae & 25 & $13,53 \pm 0,52$ \\
& 10 & $19,57 \pm 0,45 * * *$ \\
& 5 & $16,90 \pm 0,47$ \\
& 2,5 & $15,30 \pm 0,26$ \\
Aqueous Decocted of Uvaria chamae & 1 & $14,77 \pm 0,32$ \\
& 25 & $13,80 \pm 0,32$ \\
& 10 & $27,93 \pm 0,71 * * *$ \\
\hline
\end{tabular}

Each value represents the mean \pm SEM of three trials. Significance at $* \mathrm{P}<0.05$; ${ }^{* *} \mathrm{P}<0.01$; 


\section{DISCUSSION}

The anticoagulant activity of macerated and decocted $U$. chamae was evaluated in vitro against both coagulation pathways (endogenous and exogenous) in a pool of displaced normal plasmas using two global and chronometric assays, cephalin-kaolin time (TCK) and prothrombin time (TQ).

Firstly, from these two tests, the different macerated and decoction parts of this plant were incubated with the plasma for different times in order to determine the optimal incubation time to obtain a significant anticoagulant activity.

The results obtained revealed that the incubation time of $U$. chamae macerated and decocted with plasma significantly influences their anticoagulant power. Incubation of the negative control $(0.9 \% \mathrm{NaCl})$ during the different times $(1$; 5; 10; 15 and 20 minutes) did not influence the clotting time, whereas in the presence of the different macerated and decocted $U$. chamae the elongation of the TCK is significantly remarkable in time-dependent conditions.

In addition, the elongation of TQ is also significant and time dependent in the presence of these macerated and decocted. The elongation of TCK and TQ respectively suggest an inhibition of the endogenous and/or common and exogenous pathway of coagulation. These results are in agreement with those of 16,17 who showed that the prolongation of coagulation times (TCK and TQ) would be due to inhibition of the coagulation pathways.

It is clear that aqueous macerate, ethanolic macerate, and aqueous decocted $U$. chamae have anticoagulant activity positively correlated with incubation time. Thus, incubation for 15 minutes was the preferred time to obtain a high anticoagulant activity of these macerates and decocted $U$. chamae with respect to the endogenous coagulation pathway.

Incubation for 15 minutes was also the preferred time to obtain high anticoagulant activity of $U$. chamae ethanolic macerate against the exogenous coagulation pathway with the exception of aqueous macerate and aqueous decocted of $U$. chamae which showed maximum anticoagulant activity (TQ) after 20 minutes of incubation.

Indeed, these differences in optimal incubation time between extracts could be due to the extraction method, the solvent used. They could be related to the difference of active principle of the different macerated and decocted of this plant. These differences in incubation time could also be explained by the difference in the anticoagulant action of the two coagulation pathways. The synergy of action of the bioactive compounds present in these macerated and decocted would also be related to these differences in incubation time.

However, the incubation time used by 17 in them in vitro study on the anticoagulant activity of Jatropha gossypiifolia leaves is 3 to 4 times shorter than in our study. The study performed by 18 , showed that these authors used 15 minutes' incubation of the extracts with plasma when exploring the two coagulation pathways.

In addition, there is no significant difference between the Standard Plasma (31.27 s) and the negative control (36.20 s) for the TCK assay, and between the standard plasma (13.77 s) and the negative control (15.26 s) for the TQ assay. This confirms the negligible effect of Nacl on TCK and TQ elongation. However, in the presence of $U$. chamae macerate and decocted the elongation of TCK and TQ is significant and increases with concentration. This indicates that these macerates and decocted have an inhibitory action on both coagulation pathways via the inhibition of coagulation factors. However, these endogenous pathway prolongations remain lower than those of a low molecular weight heparin in the form of a ready-to-use pre-filled syringe injection solution (Lovenox® $4000 \mathrm{IU}$ anti-Xa / $0.4 \mathrm{~mL}$ ).

The elongation of TCK in the presence of different macerated and decocted $U$. chamae indicated that these extracts are capable of inhibiting factors of the endogenous pathway and factors common between the two coagulation pathways. Thus, the aqueous decocted of $U$. chamae $(25 \mathrm{mg} / \mathrm{mL})$ exerted a very significant anticoagulant activity with a TCK of 8.05 (291.83 s) times higher than that of the negative control (36.2 s) and 1.52 times higher than that of Lovenox (®) (191.93 s) at $0.25 \mathrm{mg} / \mathrm{mL}$.

In addition, the aqueous and ethanolic macerate of $U$. chamae have no inhibitory effect on this endogenous coagulation pathway. These different anticoagulant effects of the macerated and decocoated U. chamae from our study could be related to their richness in various bioactive compounds. This could be explained by their inhibitory action on factors XII, XI, IX, VIII, X, V, II and other coagulation factors ${ }^{19}$. The difference in anticoagulant effect between the extracts could be explained by the presence or absence of inhibitors of this common endogenous coagulation pathway.

These results are in agreement with those of 17 who showed the anticoagulant effect of Jatropha gossypiifolia leaves by lengthening clotting times (TCK). They also reported that this effect would be related to the inhibition of factors of this pathway.

However, the anticoagulant activity of Lovenox® $(0.49$ $\mathrm{mg} / \mathrm{mL}$ ) (TCK greater than $600 \mathrm{~s}$ ) is more pronounced than that of our various macerated and decocted products. This anticoagulant effect attributed to Lovenox® could be related to its ability to exclusively inhibit factor Xa and its weak antiIIa activity.

As for the macerated and decocted $U$. chamae $(25 \mathrm{mg} / \mathrm{mL})$, they recorded significant clotting times (TQ). These TQ extensions indicate that the different macerates and decocted exert an anticoagulant effect on this pathway. This could be due to their effect of inhibiting the exogenous and common pathway of coagulation. These anticoagulant effects could also be explained by the inhibition of factors VII, X, V II and fibrinogen 19.

Evaluation of the anticoagulant power of macerated and decocted $U$. chamae showed that the latter exerted anticoagulant power at concentrations dependent on the two coagulation pathways. This anticoagulant potency at the decocted level was significantly greater in the endogenous pathway than in the exogenous pathway.

In addition, the difference in chemical function and the diversity of the bioactive compounds contained in the different macerated and discounted products would also be at the origin of the variations in anticoagulant effect between the extracts on the one hand and between the two coagulation pathways on the other hand. These different anticoagulant effects would also be related to their high content of total phenols or to a synergy of action between molecules ${ }^{20}$. Phenolic compounds are known for their anticoagulant power. Thus, flavonoids, such as cyanidin, procyanidin $\mathrm{B} 2$, silybin, and quercetin, are believed to have an inhibitory effect on the activity of factor Xa.

In addition, flavonoids would be indicated as an appropriate therapeutic indication and bioavailable through direct inhibition of factor Xa 21 


\section{CONCLUSION}

The anticoagulant activity of macerated and decocted $U$. chamae was evaluated in vitro against both endogenous and exogenous coagulation pathways. This evaluation showed that macerated and decocted $U$. chamae exerts anticoagulant activity at concentrations dependent on these two coagulation pathways. Thus, this anticoagulant power at the level of the aqueous decocted was the most significant on these two coagulation pathways but it remains more marked on the endogenous pathway than on the exogenous pathway of coagulation. These results provide a scientific basis that justifies the use of $U$. chamae leaves in the prevention of thrombotic diseases.

\section{REFERENCES}

1. Vacheron A. «La prévention des maladies cardio-vasculaires, un enjeu majeur de santé publique ", Lucien Israël éd., Santé, médecine, société. Presses Universitaires de France; 2010. P.105119.

2. Gogoi D, Ramani S, Bhartari S, Chattopadhyay P, Mukherjee AK, Characterization of active anticoagulant fraction and a fibrin(ogen)olytic serine protease from leaves of Clerodendrum colebrookianum, a traditional ethno-medicinal plant used to reduce hypertension, Journal of Ethnopharmacology, 2019; 243:112099.

3. Batty P, Smith G, Anticoagulation, Surgery, 2013; 31(5):195199.

4. Souza ROS, Madeira JC, Chagas FDS, Parreiras LA, Santos GRC, Assreuy AMS, Mour $\sim$ AOPAS, Pereira MG, Purified polysaccharides of Geoffroea spinosa barks have anticoagulant and antithrombotic activities devoid of hemorrhagic risks, Carbohydrate Polymers, 2015; 124:208-215.

5. Bertoletti L, Mismetti P, Traitement anticoagulant initial de l'embolie pulmonaire, Revue des Maladies Respiratoires, 2011; 28(2):216-226.

6. Adjanohoun E, Ake-Assi L, Contribution au recensement des plantes médicinales de Côte d'Ivoire, Centre National de Floristique, Abidjan; 1979. P. 32.

7. Kone M, Ouattara K, Gnahoue G, Ouattara A, Coulibaly A, Study ethnopharmacological and phytochemical screening of some plants involved in the treatment of abdominal infections in the department of Kouto (COTE D'IVOIRE), Scholars Journal of Applied Medical Sciences, 2013; 1(2):56-61.

8. Koné M, Toure A, Ouattara K, Coulibaly A, Phytochemical Composition, Antioxydant and Antibacterial Activities of Root of Uvaria chamae P. Beauv. (Annonacea) Used in Treatment of Dysentery in North of Côte d'Ivoire, International Journal of Pharmacognosy and Phytochemical Research, 2015; 7(6):10471053.

9. Popoola TD, Awodele O, Omisanya A, Obi N, Umezinwa C, Fatokun AA, Three indigenous plants used in anti-cancer remedies, Garcinia kola Heckel (stem bark), Uvaria chamae P. Beauv. (root) and Olax subscorpioidea Oliv. (root) show analgesic and anti-inflammatory activities in animal models, Journal of Ethnopharmacology, 2016; 194:440-449.

10. Bamba B, Golly KJ, Ouattara A, Kone M, Doukourou DN, Benie CKD, Kamou R, Ouattara K, Anti-inflammatory activity of the aqueous macerate of leaves of Uvaria chamae (P. Beauv) (Annonaceae) on acute edema of rat paw induced by carrageenan, International Journal of Pharmacognosy and Phytochemical Research, 2019; 11(2):44-48.

11. Olakunle O, Kassim ML, Biaffra E, Andrew G, Henrietta A, Victor RG, Effects of root extracts of Fagara zanthoxyloides on the in vitro growth and stage distribution of Plasmodium falciparum, American Society for Microbiology, 2005; 49:264-268.

12. Bamba B, Benié CKD, Ouattara A, Doukourou DN, Kamou KR, Ouattara $\mathrm{K}$, Teneurs en phenols totaux, activités antioxydantes des macérés et décocté des feuilles de Uvaria chamae P. Beauv. (Annonaceae), International Journal of Biological and Chemical Sciences, 2021; 15(1):54-67.

13. Zirihi GN, Kra AKM, Bahi C, Guédé-Guina F, Evaluation de l'activité antifongique de Microglossa pirifolia (lamarck) 0. kuntze (Asteraceae) "PYMI » sur la croissance in vitro de Candida albicans, Revue de Médecine et Pharmacopée Africaine, 2003; 17:11-18.

14. Athukorala Y, Lee KW, Kim SK, Jeon YJ, Anticoagulant activity of marine green and brown algae collected from Jeju Island in Korea, Bioresource Technology, 2007; 98:1711-1716.

15. Caquet R. 250 examens de laboratoire : prescription et interprétation (9éme Ed), Masson (Paris) ; 2004. P.388-389.

16. Mao W, Li H, Li Y, Zhang H, Qi X, Sun H, Chen Y, Guo S, Chemical characteristic and anticoagulant activity of the sulfated polysaccharide isolated from Monostroma latissimum (Chlorophyta), International Journal of Biological Macromolecules, 2009; 44:70-74.

17. Félix-Silva J, Souza T, Camara RBG, Cabral B, In vitro anticoagulant and antioxidant activities of Jatropha gossypiifolia L. (Euphorbiaceae) leaves aiming therapeutical applications, BMC Complementary Alternative Medicine, 2014; 14(1):405.

18. Bijak M, Sut A, Kosiorek A, Saluk-Bijak J, Golanski J, Dual anticoagulant/antiplatelet activity of polyphenolic grape seeds extract, Nutrients, 2019; 11(1):93.

19. Elena Z, Alexey K, Exploring potential anticoagulant drug formulations using thrombin generation test, Biochemistry and Biophysics Reports, 2016; 5:11-119.

20. Silva CB., Simionatto E, Hess SC, Peres MTLP, Simionatto EL, Wisniewski JA, Poppi N R, Faccenda O, Candido ACS, Scalon SPQ, Chemical composition and allelophatic activity of essential oil from Hydrocotyle bonariensis Lam (Araliaceae), Química Nova, 2009; 32(9):2373-2376.

21. Bijak M, Ponczek MB, Nowak P, Polyphenol compounds belonging to flavonoids inhibit activity of coagulation factor X, International Journal of Biological Macromolecules, 2014; 65:129-135. 